This item was submitted to Loughborough's Research Repository by the author.

Items in Figshare are protected by copyright, with all rights reserved, unless otherwise indicated.

\title{
Decision development in facilitated modelling workshops
}

PLEASE CITE THE PUBLISHED VERSION

http://dx.doi.org/10.1016/j.ejor.2011.01.039

PUBLISHER

(c) Elsevier

VERSION

AM (Accepted Manuscript)

LICENCE

CC BY-NC-ND 4.0

REPOSITORY RECORD

Franco, L. Alberto, and Etienne A.J.A. Rouwette. 2019. "Decision Development in Facilitated Modelling Workshops". figshare. https://hdl.handle.net/2134/14643. 
This item was submitted to Loughborough's Institutional Repository (https://dspace.lboro.ac.uk/) by the author and is made available under the following Creative Commons Licence conditions.

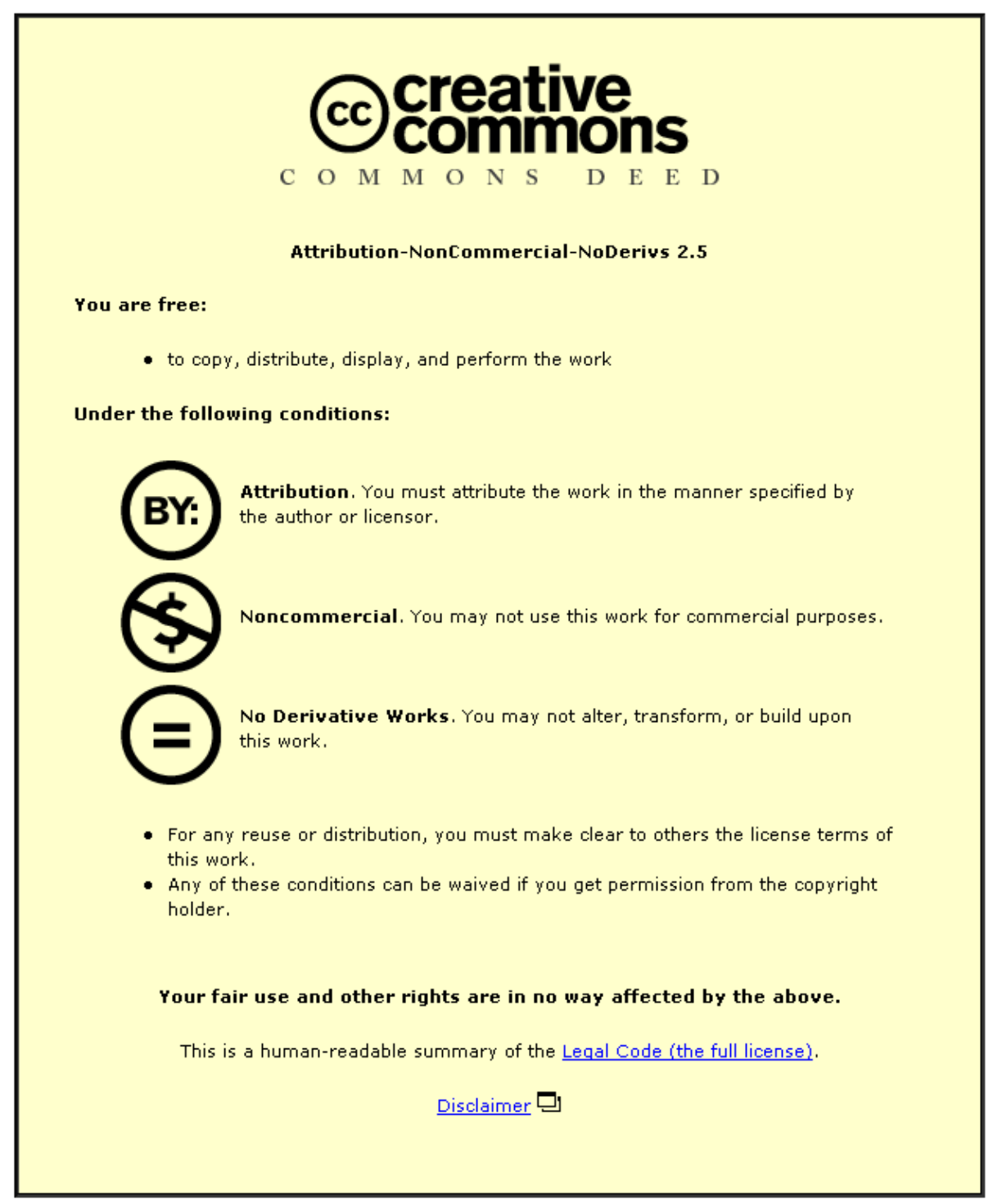

For the full text of this licence, please go to: http://creativecommons.org/licenses/by-nc-nd/2.5/ 


\title{
Decision Development in Facilitated Modelling Workshops
}

\author{
L.A. Franco ${ }^{\mathrm{a}^{*}}$, E.A.J.A. Rouwette ${ }^{\mathrm{b}}$ \\ ${ }^{a}$ Warwick Business School, University of Warwick, Coventry CV4 7AL, UK \\ ${ }^{\mathrm{b}}$ Institute for Management Research, Radboud University Nijmegen, Nijmegen, $6500 \mathrm{HK}$, The \\ Netherlands
}

\begin{abstract}
While the facilitated modelling literature recognises the importance of the group process within facilitated modelling workshops, published empirical research rarely examines their dynamic nature. In this paper, we address this gap in the literature in two ways. First, we propose to locate facilitated modelling workshops as the main focus of investigation, and adopt decision development as the analytical lens. Second, we provide guidance regarding how to implement a research strategy that is informed by such a focus. We start by mapping the different conceptualisations of decision development that seem embedded within the facilitated modelling tradition, and contrast them with theoretical models from the group communication field. Our analysis identifies a number of potentially useful areas for the study of facilitated modelling workshops from a decision development perspective, and articulates a number tentative research questions and testable propositions amenable to empirical research. Central to our proposal are research methods for the study of dynamic group processes. We thus discuss the steps required to extract group process data from facilitated modelling workshops that are usable and open to analysis. This includes a review of issues regarding research design, coding scheme development, data coding and choice of analytical techniques. Finally, we offer conclusions and briefly discuss some feasibility issues related to the implementation of our proposal.
\end{abstract}

Keywords: decision development, group process, facilitated modelling, workshops, communication.

\section{Introduction}

The 'soft' operational research approach to group decision support research and practice is well established in Europe, and has a long history of successful applications that spans over three decades (for recent reviews see Franco \& Montibeller, 2010; Mingers \& Rosenhead, 2004; Rouwette et al., 2002). This approach has sometimes been labelled 'wide-band' (Eden, 1995), because of its apparent ability to assist groups in tackling problem situations that exhibit one or more of the following characteristics: high levels of complexity due to inter-relationships between different problem elements; high levels of uncertainty originating from external or internal aspects of the problem; and significant conflict associated with both cognitive and political considerations of the problem. Helping to tackle these so-called 'messy' situations is achieved through the combined use of group facilitation and participatory modelling, or 'facilitated modelling' (FM) (Franco \& Montibeller, 2010), with a view to enabling the group to develop an increased understanding and ownership of problem formulation and its implications, together with commitment to a way forward.

\footnotetext{
* Corresponding author: Tel.: +44 (0)24765 24691; Fax: +44 (0)24765 24539; Email address: alberto.franco@warwick.ac.uk (L. Alberto Franco)
} 
Franco, L.A. \& Rouwette, E.A.J.A. (2011). Decision Development in Facilitated Modelling Workshops. Submitted to the European Journal of Operational Research.

The literature is replete with in-depth case studies of FM interventions (e.g. Barcus \& Montibeller, 2008; Connell, 2001; Franco et al., 2004; Ormerod, 1995; Vennix et al., 1996; White, 2009). Typically, these studies offer thick descriptions of the context of the intervention, the rationale for the intervention design, the chronology of the intervention, and rich, in-depth reflections about the intervention effects from the perspective of the 'intervener', the 'intervened', or both. Furthermore, it is not uncommon for effects reported in these cases to be attributed to the intervention. Yet with few notable exceptions (e.g. Ackermann \& Eden, in press), we know very little about what actually happens within FM interventions in general, and FM workshops in particular. For example, seldom do we read about how a particular FM workshop design affects the way group decisions are developed; or how participants interpret and respond to FM workshop rules, methods and tools during group interaction. This is somewhat surprising, as workshops are the principal means through which FM interventions are deployed in practice (Mingers \& Rosenhead, 2004).

The study of FM workshops would allow us to address a multitude of issues regarding the role and impact of FM approaches in supporting groups. For example, we can examine how different aspects of the problem situation are introduced, developed, and agreed upon by group members, and assess how the deployment of a particular FM workshop design affects this process. We can study how conflict arises in the workshop, and how the FM analyst and approach enable or constrain the group members' ability to manage it. We can also study what strategies FM analysts use to manage the workshop process and the extent to which they are successful in helping the group develop a sense of common purpose. These issues are complex ones, but direct examination of FM workshop processes can provide insight into the mechanisms through which FM approaches impact the working and performance of groups.

This paper thus attempts to address this gap in the literature on what happens in FM workshops by proposing to locate these settings as the main focus of investigation, and adopt decision development as the analytical lens. We use the term 'decision development' to refer to how group interaction creates and elaborates decisions over time (Poole \& Baldwin, 1996). It is not, however, directly concerned with the longer-term development of the group as a unity (see, for example, Wheelan, 1994). Our proposal pays attention to the temporal patterns in group decision making within FM workshops and, because it establishes the temporal order of events within the workshop, it also facilitates causal analysis. Specifically, in this paper we address three broad interrelated questions: (1) What patterns of decision development characterise FM workshops? (2) What is the relationship between these decision development patterns and FM workshop inputs and outputs? (3) How can we empirically study decision development in FM workshops?

The study of decision development in FM workshops attends to recent calls for alternative ways to evaluate the impact of FM approaches that go beyond the sole reliance on post-hoc reflective accounts or pure anecdotal evidence of their use (Franco \& Montibeller, 2010; Rouwette et al., 2002). It can offer unique insights into how decision development unfolds 
Franco, L.A. \& Rouwette, E.A.J.A. (2011). Decision Development in Facilitated Modelling Workshops. Submitted to the European Journal of Operational Research.

in FM supported groups by providing information about what FM participants actually do in workshops. The resulting data can be used to capture actual behaviours and workshop structures used during the decision development process (using frequencies of participants' actions), and how and when they enable or undermine the achievement of group outcomes (focusing on the sequential nature of group interaction). In addition, besides gaining a better understanding of the decision development process itself, an examination of what goes on within FM workshops will enable researchers to identify modelling and facilitation strategies that are deemed effective in supporting group work, as well as those which should be avoided. This information can be used to identify the circumstances under which FM workshops are likely to be successful, and determine how FM analysts and users can be better trained to effectively deploy FM processes and tools.

The remainder of the paper is organised as follows. In the next section we survey different conceptualisations of decision development that seem embedded in the FM tradition, and identify a few conceptual frameworks of decision development advocated by prominent FM academic-practitioners. We then relate these frameworks to theoretical models of decision development in the group communication field, which has a long history of direct study of dynamics processes in groups. This analysis helps us to identify areas of opportunity for the examination of decision development in FM workshops, and address the first two questions stated earlier. It also enables us to articulate some tentative research questions and testable propositions amenable to empirical research. Next, we address the third question above by discussing the required steps in extracting group process data from FM workshops that is both usable and open to analysis. This includes a review of issues regarding research design, coding scheme development, data coding, and choice of analytical technique. Finally, the last section offers conclusions and a brief discussion of feasibility issues regarding the implementation of our proposal.

\section{Conceptualisations of decision development in the FM tradition}

In this section we consider those conceptualisations of decision development which have informed specific facilitated modelling approaches. Theoretical frameworks that treat decision development at a more general level (see, for example, Brugha, 1998), while relevant to our subject of study, are beyond the scope of this paper and thus will be excluded from the discussion that follows.

Although the status of any FM approach is said to be conditionally prescriptive (Franco \& Montibeller, 2010), their design is founded upon explicit notions, or implicit hunches, of how group decision-making occurs in practice. According to Eden (1992), a design for a decision support procedure should at least reflect on "the nature of group decision-making as a process, the nature of decision-making in organisations, ... and the nature of support and intervention" (p.213, our emphasis). Eden proposes that decision support design be based on a descriptive conceptualisation of group decision-making, instead of on a normative model, to avoid starting from considerations of an idealised world that may prove to be difficult to attain in practise. Attention to the descriptive aspects of decisionmaking requires an understanding of the different ways in which decisions develop within 
Franco, L.A. \& Rouwette, E.A.J.A. (2011). Decision Development in Facilitated Modelling Workshops. Submitted to the European Journal of Operational Research.

groups or organisations. As Friend (1995) notes, decision-making in practice draws those concerned into continuing interactions, spanning several decision phases that together form a broader developmental process.

We would thus expect developers of FM approaches to be quite explicit about what theories of group decision development underlie their methods. However, there are surprisingly few accounts concerning this aspect published in the extant literature. For example, Checkland's (1999) 30-year retrospective of Soft Systems Methodology does not mention group decision development aspects at all. Vennix’s $(1996,1999)$ work on Group Model Building identifies deficiencies in unsupported group interaction, as well as attitudes and skills required for facilitating Group Model Building workshops. Yet he does not discuss decision development processes explicitly. Indeed, if we refer to the main FM scholars cited in Franco and Montibeller's (2010) recent invited review in this journal, we find that only Eden (1986, 1992), Phillips (1989, 1990), and Friend (1995, 1997) are explicit about their assumptions of group decision development in relation to their methods: Strategic Options Development and Analysis (SODA), Decision Conferencing, and Strategic Choice Approach (SCA), respectively.

Eden (1982; 1986; Eden \& Ackermann, 1998) describes decision development in groups as a unitary cycle between four focus points: (1) trying to make sense of the problem, in which the breadth of the problem of concern is considered, conflicting beliefs are discussed and regions of critical uncertainty established; (2) defining the problem, in which a consensual representation of the problem is sought; (3) solution finding, where a portfolio of solutions is identified; leading to (4) constructing a new problem. Progression through these cycles involves managing 'order' both in terms of content (achieving order by representing the problem) and social relationships (developing a problem representation that the parties involved can accept) (Eden, 1992).

Phillips, on the other hand, conceptualises group decision development as a dual process. A description of how a group tries to accomplish its objectives while at the same time attending to its emotional life is given by Phillips and Phillips (1993): "understanding the emotional life of the group is the key to working effectively in a group” (1993, p.537). An important driver for group emotions is the tension that exists between members' individual desires and what is best for the group. Members have relational ties to others in the group and a particular role to play, which shapes their emotional reaction to the group process. In turn, the group process may have implications for the relations between members, for instance with regard to distribution of resources or influence. Phillips' description of the task and emotional elements as separate but intertwined aspects of group decision development is not dissimilar to Eden's notion of managing order within a group.

Friend (1993) offers an alternative conceptualisation of group decision development. His conceptual framework is located within the context of multi-organisational groups, which he sees as clearly different from many of the groups with which approaches such as SODA and Decision Conferencing are used, i.e. groups drawn from medium to large organisations 
Franco, L.A. \& Rouwette, E.A.J.A. (2011). Decision Development in Facilitated Modelling Workshops. Submitted to the European Journal of Operational Research.

with clearly established decision-making hierarchies and accountability systems. Friend finds that in the multi-organisational context "decision situations would be continually changing, as the more urgent decisions were taken, under the pressure of external events, while other choices, often of quite a different character, would arise to take their place” (p.593). In his view group decision-making comprises an ongoing stream of interconnected decision areas, a process shaped by networks of stakeholders and different types of uncertainty. Progress depends on managing interests of intra- or inter-organisational stakeholders, which may conflict. This, in turn, is founded upon an iterative cycle of shaping decision areas and their relations, designing solution packages, comparing them against criteria, and choosing a decision package that allows decision makers to make a step forward (Friend \& Hickling, 2005).

\section{Theoretical models of decision development in the group communication field}

The views offered by Eden, Phillips, and Friend can be contrasted with theoretical models of decision development that are well-established in the group communication field (see, for example, Poole, 1999; Poole \& Baldwin, 1996), which has a long history of direct study of dynamic group processes. Although decision development models have been categorised in different ways in this literature (e.g. Chang et al., 2006), for the purpose of our discussion here we will distinguish two broad categories of models: phase and social construction. These are briefly discussed next.

\subsection{Phase models}

Most of the early studies on group decision development in the group communication field fall within the category of phase models (Fisher, 1970; Mabry, 1975). These studies depict group decision development as passing through a series of identifiable phases, defined as a set of coherent activities that serve some decision-related function (e.g. problem analysis, solution development) or socio-emotional expression. Most phase models posit a single, unitary sequence of phases, as a response to an ordered series of problems the group faces in developing a decision. In contrast, multiple sequence models posit that groups may also follow more complicated paths, in which episodes repeat themselves when groups cycle back to earlier phases. Multiple sequence studies do not rule out the existence of unitary sequences, but assume that this is only one of the possible decision paths groups may follow (Poole, 1983a, 1983b).

More elaborated phase models depict decision development as a continuous process, rather than as a series of unitary or multiple discrete phases. One feature of these models is the regular cycling of socio-emotional activity within the group, which reflects the alternation of attention between task and social aspects of group functioning (Bales, 1951; Scheidel \& Crowell, 1964). For example, Poole's (1983b) continuous model depicts decision development as a series of intertwining threads of activity that evolve simultaneously and interweave in different patterns over time. He proposes three threads of activity: task process activities (e.g. problem analysis, solution evaluation), relational activities (e.g. conflict) and topical focus. When these three threads develop in a coordinated way, the coherent phases assumed by unitary or multiple sequence models result. However, when 
Franco, L.A. \& Rouwette, E.A.J.A. (2011). Decision Development in Facilitated Modelling Workshops. Submitted to the European Journal of Operational Research.

the threads are not coordinated and the group shifts behavioural patterns very rapidly, there will be no coherent pattern and no phases can be discerned. Decision paths are determined by the interplay of two forces: the underlying logical requirements for task completion (e.g. a sequence of 'problem diagnosis-problem definition-option generation-option evaluation-implementation planning' for a problem solving group), and a set of contingency factors (e.g. task and group characteristics).

Finally, a number of phase models focus on the general strategies behind group decision behaviour and on shifts in strategy and direction, rather than on detailed phases of decision development. For example, Scheidel and Crowell (1964) posit that groups develop ideas through a "reach-test' type of motion" in which one member advances an idea and then the group elaborates on it at length and expresses approval before going on to the next idea. They propose that this cycle of introduction, discussion and anchoring of group positions is important to building commitment to the group’s decision. MacKenzie (1979) describes decision development in terms of various milestones groups must obtain to complete a task. Associated with each milestone are related behaviours and messages that can be used to determine which milestone a group is working on as well as group progress towards a decision. Milestone structures are part of the model that also includes role structures and communication structures. The model tries to account for decision development in terms of dynamic changes in these structures.

An often-cited phase model is Gersick's $(1988,1989)$, who presents a macro-level view of decision development as a series of phases of uniform group work punctuated by transitory periods of upheaval and quantum change. Specifically, her model identifies a two-phase developmental pattern of decisions. The first one represents a period of inertia, the direction of which is set early in the period. Then at some midpoint the group undergoes a transition that sets a revised direction for the second phase. In her research, Gersick found that these midpoint transitions coincided with the halfway point of the group's allotted time. When the transition is successful, Gersick argues, the group settles into a phase of inertia; if it is not, the group continues enacting problems that prevented progress in the previous phase.

\subsection{Social construction models}

Knowing the order of phases a group follows in their decision developmental path does not necessarily tell us how the sequence developed as it did. Social construction models attempt to fill this gap by accounting for how group decisions are constituted in and through interaction, how contingency factors are mediated by member reactions, and how interaction advances the group towards the decision (Poole, 1985).

Several scholars have studied how decisions are socially constructed. For example Schwartzman's (1989) study highlights varied ways in which groups actively construct decisions. These include labelling a segment of discussion 'decision making', treating statements as assertions or arguments rather than some other type of speech act, and confirming agreement on a conclusion to bring the segment of discussion to an end. She 
Franco, L.A. \& Rouwette, E.A.J.A. (2011). Decision Development in Facilitated Modelling Workshops. Submitted to the European Journal of Operational Research.

also notes that decisions may be made post hoc, during post-meeting discussions in which group members make sense of their meeting by formulating what was done as a decision. Fisher and Stutman ((1987) analyse 'breakpoints' as tools for social construction. Breakpoints are key junctures at which the group has the chance either to change direction or to reaffirm its current direction. At breakpoints group members seek to influence discussion through prospective and retrospective routing statements: the former try to move the discussion in a certain direction; the latter try to set direction by summarising and reformulating what the group has done. Whether the group redirects or reaffirms its current decision development path depends on how successful routing statements are in influencing the discussion.

Another social construction model is offered by Poole and Doelger (1986), who provide an account of how structures and structuring processes in group interaction mediate decision development paths. Drawing on Giddens' (1984) structuration theory, the model distinguishes between the group decision as a 'system', the observable patterns of group members' behaviours, and the 'structures' group members use to generate and sustain the (group) decision. Structures are recipes for acting comprising a configuration of rules and (material/social) resources used by to bring about action (Giddens, 1984). Examples of structures are (Poole, 1985): group members' representations of the nature of the task comprising both content aspects (e.g. member's idiosyncratic understandings of the problem of interest) and process aspects (e.g. a preferred decision logic for working on the task). Other structures are the various discursive rules group members use to make their arguments articulate and consistent during group discussion (Hutchby \& Wooffitt, 1998; Poole, 1985). Members invoke or 'appropriate' these structures to guide their group activity, which constitutes a path to a group decision and the decision itself. In turn, these structures are themselves produced and reproduced as they are used by group members to generate a decision. This double constitution of the decision system and its underlying structures represents a continuous process of 'structuration' (Poole et al., 1996), which is said to have an effect on the eventual decision development path taken by the group.

The structuration process works like this (Poole \& Baldwin 1996): group members advance various task representations, and the group constructs one or more representations through interaction. Coherence structures (e.g. discursive rules) are applied to give continuity and cohesiveness to the discussion. If the group converges on a single representation that adequately addresses the requirements of the task, then a relatively simple decision development path will result. More complex paths will result when more than one task representation is used at different points during the discussion, when two or more representations compete with each other, or when a representation is not adequate to deal with objective task demands and the groups experiences failure or must cycle back to rework its representation. Non-organised periods of interaction result when the group's appropriation of coherence structures is not sufficient to overcome problems introduced by difficulties with the task or conflict among task representations. Therefore, differences in decision development paths among groups are explained according to the particular pattern of structural appropriations each group develops. These differences are influenced by, 
Franco, L.A. \& Rouwette, E.A.J.A. (2011). Decision Development in Facilitated Modelling Workshops. Submitted to the European Journal of Operational Research.

among other things, characteristics of the group (e.g. group composition) and its situation; the nature of the structures that are appropriated (e.g. a group using a majority rule for decision making will have a different decision path from a group using a consensus rule); the degree of consensus on which structures should be used and how they are used; and group members' degree of insight into structures (greater insight into structures allows better control and ability to adapt a structure to contextual demands).

\subsection{Linking FM conceptualisations of decision development to group communication models}

From our preceding discussion, it would appear that Eden's (1982) original conceptualisation of sense-making, problem-defining, solution-finding and problemconstructing implies a linear progression from one stage to the other, and thus resembles a unitary sequence phase model. Similarly, the shaping-designing-comparing-choosing stages embedded within Strategic Choice (Friend \& Hickling, 2005) can be linked to a phase model. Unlike Eden however, Friend explicitly argues that multiple paths and cycling between stages are possible due to a group’s particular response to their decision context and the constraints imposed by outside factors (Friend \& Hickling, 2005). Thus Friend's conceptualisation of decision development bears a resemblance to a multiple sequence phase model.

The alternation of attention to task, content and relational aspects of group decision development is made explicit by Phillips (1989; Phillips \& Phillips, 1993). Likewise, Eden $(1990,1992)$ attaches significant importance to the need to attend to the balance between managing content and maintaining or building order of social relationships. Overall, the notions of task, content and relational aspects bear a resemblance to those advocated in more complex phase models (e.g. Poole 1983b).

The notion of group decision-making as a socially constructed activity is widely accepted within the facilitated modelling field (Franco and Montibeller 2010). For example, Eden (1993) argues that models build 'on-the-spot' by the group, which is a core aspect of FM workshops, become 'transitional objects' (De Geus, 1988) that enable the social construction of a shared reality for group members. However, more elaborate conceptualisations of social construction processes are, to the best of our knowledge, lacking in the FM literature. Nevertheless, it is possible to relate some of the theoretical ideas underlying social construction models to FM conceptualisations. Consider the use of structures such as decision logics employed by group members to generate and sustain the group decision (Poole, 1985; Poole et al., 1996; Poole et al., 1985). Within the FM field, Rohrbaugh and colleagues posit that group members evaluate the effectiveness of Decision Conferencing workshops based on multiple competing criteria (consensual, political, rational, empirical) (McCartt \& Rohrbaugh, 1989; Reagan \& Rohrbaugh, 1990). It is plausible that these criteria represent a set of decision logics that group members also use, in interaction, to guide their work. Phillips and Phillips (1993) provide several examples of how emotionally charged content is suddenly made explicit by a group member (e.g. when, during a discussion, a group member can no longer contain his anger about what he 
Franco, L.A. \& Rouwette, E.A.J.A. (2011). Decision Development in Facilitated Modelling Workshops. Submitted to the European Journal of Operational Research.

perceives to be evading answers from another member). It does not seem too far-fetched to interpret these occurrences as potential breakpoints (Fisher \& Stutman, 1987), after which a new decision development path might be followed by the group, which in turn might facilitate the emergence of a shared reality.

Table 1 depicts the most important relations between the FM conceptualisations of how group decisions develop and the theoretical models of decision development from the group communication literature. As the table suggests, the conceptualisation of decision development embedded within Strategic Choice appears to be consistent with phase models. Eden's earlier conceptualisations of group problem solving can also be linked to phase models, but subsequent writings (e.g. Eden \& Ackermann, 1998) present a more elaborated picture of decision development which places SODA assumptions closer to those contained in social construction models. Finally, Phillips' insights about the nature of facilitated work groups imply that the assumptions embedded within his version of Decision Conferencing can be related to both phase and social construction models.

\section{PLACE TABLE 1 HERE}

The mappings identified in Table 1 are influenced by our own reading of the FM literature (particularly the work of Eden, Phillips, and Friend) and thus are, to an extent, idiosyncratic. Notwithstanding this potential bias, our preceding discussion should have made clear that certain notions of decision development are indeed embedded within the FM field, and that it is possible to relate these notions to theoretical models of decision development from the group communication field. In the next section we explore some potentially useful areas for the study of FM workshops from a decision development perspective, and articulate some tentative research questions and testable propositions amenable to empirical research.

\section{Studying decision development in FM workshops}

In this section we outline four potential areas for studying FM workshops from the decision development perspective. These are: decision paths; contingency factors influencing decision paths; social construction processes influencing decision paths; and the link between decision paths and outcomes. Recall that our aim in this paper was to address three broad interrelated questions. Whereas the first area of study concerns the first question on decision development patterns, the other three areas address the second question on the relation between patterns and inputs and outputs. Research within any of these areas can be informed by either of the phase or social construction models discussed in the previous section. We discuss each in turn.

\subsection{Studying decision paths}

As noted in our discussion of phase models (see Section 3.1), group communication studies suggest that decision paths can follow unitary, multiple or more complex sequences. The empirical evidence from the laboratory and the field suggests that only a small portion of decisions in a given sample will approximate the unitary rational decision 
Franco, L.A. \& Rouwette, E.A.J.A. (2011). Decision Development in Facilitated Modelling Workshops. Submitted to the European Journal of Operational Research.

sequence (e.g. Jackson \& Poole, 2003; Mintzberg et al., 1976; Nutt, 2008; Poole \& Baldwin, 1996; Poole \& Roth, 1989a). These results are important to the study of FM workshops because they correspond to studies of groups working without any form of decision support. One would expect that for the case of supported groups working within an FM environment, a higher proportion of decisions would follow the unitary sequence. This is a plausible proposition, as most FM workshops are designed with an ideal unitary sequence in mind. For example, a 'whole' SCA workshop would be planned to broadly follow a 'shaping-designing-comparing-choosing' sequence. An interesting testable proposition would thus be to examine whether these designed or intended unitary sequences are indeed observed in FM workshops. We can also examine what other decision sequences can occur both in the field and the laboratory.

Alternatively, we could study decision paths in FM workshops from a more macro-view of decision development. A stable finding in studies of the operation of critical events as transition periods between two broad phases of inertia (see Section 3.1) is that these periods coincide with the halfway point in a group's work, as members evaluate what they have done up to that point in time and try to get organised to finish their tasks (Chang et al., 2003; Gersick, 1989). The empirical evidence also indicates that a group's progress from one phase to the next is triggered more by group members' awareness of time and deadlines than by completion of an absolute amount of work before the transition (Lim \& Murnighan, 1994; Waller et al., 2002). Again these findings correspond to unsupported group decision making. An interesting research possibility would thus be to empirically test these propositions in a FM workshop environment. This could help us gain an insight into the influence FM participants, the FM analyst and models might have in the temporal trajectory of group decisions (see also Section 4.3 below).

\subsection{Studying contingency factors influencing decision paths}

What accounts for the existence of different decision paths? From the group communication literature we have learned that differences in decision development can be explained by contingency factors such as group and task characteristics, degree of conflict in the decision, and degree of uncertainty about the situation (e.g. Mintzberg et al., 1976; Nutt, 1984; Poole, 1983b; Poole \& Roth, 1989b). Studies on the use of group decision support systems have also noted the degree of procedural support provided by these systems as a contingency factor affecting decision paths (e.g. Poole \& Holmes, 1995). The findings suggest that enforcement of procedures results in simpler decision paths. The findings also indicated that only a small proportion of decision paths resemble unitary sequences, and that different types of procedural support led to distinctly different decision path types. These findings are particularly relevant to the study of FM workshops. Like group decision support systems, FM approaches also offer procedural support and impose a degree of structure upon the group's work. Furthermore, Franco and Montibeller (2010), argue that the type of procedural support and degree of structure imposed varies within and across different FM approaches. For example, SODA workshops can be designed to be deployed with or without computer support, and the rules for collecting and structuring group members' contributions via mapping are relatively flexible. On the other hand, 
Franco, L.A. \& Rouwette, E.A.J.A. (2011). Decision Development in Facilitated Modelling Workshops. Submitted to the European Journal of Operational Research.

Decision Conferencing workshops always make use of computer support, and group members' contributions are processed following strict rules based on multi-attribute decision theory. We would expect that these differences in procedural support will produce simpler and essentially different decision paths. Thus an interesting testable proposition would be to examine what effect the different types of procedural support embedded within different FM workshop designs have on decision development paths. Furthermore, it would be interesting to contrast the decision paths that may result from using different FM workshop designs, and relate these paths to outcomes (discussed in section 4.4).

\subsection{Studying social construction processes influencing decision paths}

Perhaps the most interesting sources for deriving testable propositions are social construction models. For example, we could address how, within an FM workshop, group members develop a shared representation of a problem situation of interest. Shared representations of problems in the form of collective cognitive maps have largely been studied in the FM literature (e.g. Eden, 1988, 2004; Eden \& Ackermann, 1998). However, their empirical examination has been from a static, rather than dynamic or developmental, perspective (for a notable exception see Ackermann and Eden, in press). As a result, many interesting questions remain unanswered: What is the process through which a group member's cognitive map is accessed by FM participants? How do FM participants learn where knowledge resides within the group? How do individual group members' cognitive maps converge to form a collective representation? Direct examination of decision development interaction should help us answer these questions.

Another possible source that can inform our study of social construction processes in FM workshops comes from research on the use of breakpoints -opportunities for radical group progress which in an FM context can be triggered by the FM analyst, the group members, or both. Fisher and Stutman (1987) suggest that at breakpoints group members redirect or reaffirm the decision development process through prospective or retrospective routing statements (see Section 3.2). They found that prospective routing statements are most likely to be effective if they are timed properly, are tied to a substantive issue, and not overly controlling or authoritarian, and do not try to project too far ahead; whereas retrospective routing statements are most likely to be effective if they exhibit a positive tone about previous group interaction. These findings suggest guidelines for effective action and thus amenable to empirical testing in an FM workshop. For example, we can investigate the routing statements used by both the FM analyst and the group members during interaction, and examine how effective these statements are in influencing the group discussion and the decision path.

Another useful source are studies of structuration processes. As discussed in Section 3.2 differences in decision paths among groups are explained by the particular ways in which each group appropriates structures used to generate the decision. Here, studies of groups interacting with the technology-driven structures embedded within group decision support systems (e.g Poole \& DeSanctis, 1992) can inform the examination of social construction processes in FM workshops. For example, if we focus on how structure influences action, 
Franco, L.A. \& Rouwette, E.A.J.A. (2011). Decision Development in Facilitated Modelling Workshops. Submitted to the European Journal of Operational Research.

we can study how the structures designed into an FM workshop (e.g. methods for problem structuring and option evaluation, facilitation procedures, models) shape and constrain the behaviour of group members in the workshop and, hence, decision development.

Alternatively, if we focus on the role of agency in the operation of structures, we can study how group members use the structures to guide decision development. Typically, the FM analyst will design the structures to be deployed in a particular manner by group members, and will invoke these structures for analysis, display or interaction during the workshop. Whether group members will actually reproduce them (i.e. use them in the way they are intended) is, however, a matter for empirical investigation. Group members may appropriate the structures as intended, or adapt them to their specific circumstances (i.e. produce new structures), or reject them. Thus we can investigate whether group members 'appropriate' FM workshop structures in unintended ways. Furthermore, we can investigate whether group members' interaction, with the FM analyst and with another, gives rise to other (new) structuration processes that counteract or undermine decision development.

Overall, a closer examination of social construction processes may shed light on the nature of the generative mechanisms that drive decision development and ultimately group outcomes in FM workshops.

\subsection{Studying the link between decision paths and group outcomes}

The relationship between decision paths and group outcomes provides an excellent area for the study of FM workshops. The major tenet in group communication studies is that deviation from theoretical patterns of decision development signals problems or failure in a group, and there is some empirical evidence that supports this. Hirokawa $(1983,1985)$ identifies clear differences in decision paths among effective and ineffective problemsolving groups. Effective groups engaged in problem analysis at the beginning of their sessions, solution discussion peaked in the middle, and evaluation peaked near the end (resembling a unitary sequence). Sambamurthy \& Poole (1992) show clear differences in conflict management paths among high-consensus and low-consensus decision-making groups. They found that groups with most (positive) consensus change followed paths that first engaged in focused discussion, then had a period of open opposition and clash, then engaged in problem-solving or negotiation to resolve the conflict (Sambamurthy \& Poole, 1992). Poole and DeSanctis (1992) studied how groups in interaction appropriate the structures available in group decision support systems. They found that high consensus groups followed 'faithful' rather than 'ironic' appropriation paths (i.e. they used the structures as intended by the system design).

The above results seem to suggest that decision paths resembling a normative phase sequence lead to successful outcomes. This is encouraging, as FM workshops are typically designed on this basis and we would thus expect them positively influence group outcomes. This proposition can be empirically tested with studies similar to those discussed above. This is a very important area for future research that has been a neglected 
Franco, L.A. \& Rouwette, E.A.J.A. (2011). Decision Development in Facilitated Modelling Workshops. Submitted to the European Journal of Operational Research.

subject to date. It will enable the identification of outcomes produced by various decision paths and their dependence on various FM workshop designs and other contextual variables.

Adopting a decision development lens to study FM workshops requires significant research effort and a particular approach to data treatment and analysis. Next, we turn our attention to methodological concerns associated with conducting decision development research, with the goal of pointing the interested researcher towards the issues that must be considered at each step of the research process.

\section{Methodological considerations}

This section concerns the third question we aim to address in this paper: on how to empirically study decision development in FM workshops. We discuss issues of research design, coding scheme development, and data coding and analysis. We will primarily draw on the formulations of Poole and colleagues concerning group communication research methodology, as well as methods to study process-level phenomena (e.g. Folger et al., 1984; Holmes \& Poole, 1991; Poole et al., 2000). Rather than repeat what has been done in the past, our goal is to identify methodological issues at each step of research into decision development, and point to sources where useful guidelines can be found.

\subsection{Research design}

The study of FM workshops proposed here can be implemented by adopting a research strategy based on either field case studies or laboratory experiments designed to explore the relationships between FM workshop inputs (and context), decision paths, and outcomes. Field experiments are less feasible as it would be quite difficult to manipulate FM workshop designs and record decision development processes for large numbers of groups within or between organisations (although see Huz et al., 1997).

The case study approach can be used to focus on a single or small set of groups participating in FM workshops, and systematically examine its behaviour over time. The purpose of this approach is to describe the decision development process of a group, and its strength lies in the depth of understanding that could be gained. It also avoids the potential biases associated with averaging interaction data across groups to reach conclusions about the decision development processes of any one group. For example, Kuhn and Poole (2000) used a longitudinal case study approach to identify different conflict management patterns in 11 ongoing, naturally occurring workgroups from two large organisations, and relate them to decision effectiveness using multiple indices that tapped group member, facilitator and external observer viewpoints.

Laboratory experiments examine multiple groups within each experimental condition, and combine interaction data across groups to look for similar patterns within conditions and differences in patterns across conditions. Experiments are typically used when the researcher is interested in linking decision development processes to inputs or outcomes, or when testing the mediating role of decision development processes is desired. For 
Franco, L.A. \& Rouwette, E.A.J.A. (2011). Decision Development in Facilitated Modelling Workshops. Submitted to the European Journal of Operational Research.

example, in a study of group problem formulation, discussion content was coded for groups using a structured-argument approach versus a computer-driven decision support system, and then compared across experimental conditions (Niederman \& DeSanctis, 1995).

In choosing whether to use experiments or case studies, we must consider the objectives of the research and the feasibility of collecting data. In addition, we must also consider issues of generalisability, realism, and control of extraneous factors and causality (McGrath, 1982). Whereas experiments provide the highest level of control and moderate generalisibility, they provide it at the expense of realism. Case studies provide high realism, but their focus on a single or few groups limits generalisibility and control. For an interesting debate in this journal regarding the appropriateness of different research designs for the study of FM approaches see Eden (1995; 2000) and Finlay (1998).

Either approach will require careful consideration of data collection. In the discussion that follows we assume that interaction data is captured via audio or videotape, and most likely transcribed -for an excellent discussion of data collection issues in group process research see Weingart (1997). Extracting usable data from these sources requires two steps: developing a coding scheme, and applying it to identify relevant behaviours for subsequent analysis. These steps are discussed next.

\subsection{Coding scheme development}

To study group decision development in facilitated modelling workshops, one must first be able to characterise the stream of raw group interaction that takes place within that environment. Consider, for example, the interaction segments shown in Figure 1. These have been extracted from two separate FM workshops in which we have been recently involved. Excerpt 1 is drawn from a SODA workshop, and shows participants interacting with the facilitator in order to clarify and capture the meaning of a new statement that will be entered into the model. Note how participants, aided by the facilitator, jointly explore ways to rephrase the statement so that it reflects the meaning intended by the group. The segment ends with group members laughing, which can signal the release of tension built up in the group until that point. Excerpt 2 is taken from a Group Model Building workshop and illustrates a transition period from model building to solution analysis. Here, the facilitator uses the model to help the group identify potential 'intervention' points to change the system.

\section{PLACE FIGURE 1 HERE}

The analysis of short group interaction segments such as those shown in Figure 1 is relatively unproblematic (particularly if video/audio recordings of the workshops are available) and allows many questions to be explored. For example, we could analyse the 'functions' that each of the participants' statements are trying to serve (e.g. decisionrelated, process-related). We could also analyse relational aspects of the interaction (e.g. degree of conflict or cohesiveness exhibited in the group). Or we could examine how the 
Franco, L.A. \& Rouwette, E.A.J.A. (2011). Decision Development in Facilitated Modelling Workshops. Submitted to the European Journal of Operational Research.

model is actually being used by the facilitator or the group members. With so many avenues for analysis available, and given that actual FM workshops contain fairly long interaction segments, a formal approach is needed. To begin with, once FM workshop interaction data is collected, it then needs to be characterised so that it is amenable to analysis. This can be accomplished with the help of coding schemes that classify behaviours in accordance to a set of carefully defined, pre-established categories (Hirokawa, 1988, p.231).

Several discussions of how to construct a coding scheme can be found in the group communication literature (e.g. Folger et al., 1984; Poole et al., 1987). Two general approaches can be distinguished: the first one involves development of an exhaustive, logically complete, classification system that can be applied to different types of groups and tasks such as Interaction Process Analysis, (Bales, 1951) and Time-by-Event-byMember Pattern Observation (Futoran et al., 1989) systems. The second approach indexes group behaviours associated with performing the specific task at hand. Coding schemes such as the Decision Functions Coding System (Poole \& Roth, 1989a), and the Group Working Relationships Coding System (Poole, 1983a) are examples of task-specific systems: the former is designed to classify group decision making behaviours in terms of problem-oriented, solution-oriented, and process-oriented activities; the latter is designed to classify conflict management behaviours in terms of focused work, critical work, conflict related activities and integration.

Task-specific coding schemes can be can be developed inductively by deriving coding categories from the data ('bottom-up') (e.g. Hirokawa \& Pace, 1983); alternatively, theory can be used to specify categories deductively, which are then written into rules (e.g. Weingart et al., 1996). In practice, deductive and inductive approaches are combined (see, for example, Bales, 1951; Poole \& Roth, 1989a, 1989b). In Appendix 1 we provide a short overview of coding schemes that may be of interest to FM researchers. The overview shows a variety of foci such as socio-emotional process, support or disagreement with proposals, development of arguments, elaboration of information, and categories of content covered.

Other considerations when developing coding schemes can be found in Poole et al (1999; 2000) and Weingart (1997). Here we will mention two key considerations: the degree of equivocality embedded in the categories, and the type of meaning the coding scheme is intended to capture. With regards to the equivocality of classification categories, the general recommendation is for these to be mutually exclusive and exhaustive (e.g. Holsti, 1969). However, the fact that group behaviour may have several layers of meaning has raised the need for multifunctional and multilevel coding systems, such as the SYMLOG system developed by Bales and Cohen (1979). As to the type of meaning captured by coding schemes, Poole et al (1999) distinguish 'observer-privileged' meanings from 'subject-privileged' meanings. Observer-privileged meanings are those available to outside observers, whereas subject-privileged meanings are those shared understandings that participants would have about the same interactions. Coding systems designed to acquire 
Franco, L.A. \& Rouwette, E.A.J.A. (2011). Decision Development in Facilitated Modelling Workshops. Submitted to the European Journal of Operational Research.

either type of meanings will imply different approaches to their validation (see next section).

Our preceding discussion covers key issues associated with the development of coding schemes. A limitation of most coding systems is that they reduce the usually rich and complex stream of group interaction into a single dimension of meaning. To overcome this limitation, interaction can be coded along several tracks each focusing on a different dimension of meaning. A good example of this type of coding can be found in Poole's studies (1983a, 1983b) of decision development.

\subsection{Coding data}

There are two discrete steps in coding interaction data. First, the researcher has to identify units of group interaction amenable to theoretically meaningful interpretation. Second, the researcher has to assign meanings to those units using relevant contextual cues, and carry out this interpretation process in a manner that is as consistent and accurate as possible. Below we discuss each of these aspects in turn, including issues of unitizing reliability, classification reliability, and validity.

A coding unit can include a single utterance, sentence, theme, speaking turn, and timed segments (Folger et al., 1984; Frey et al., 1992). The appropriateness of any unit of analysis will depend on the particular aspects of decision development the researcher wishes to study. For example, to code problem structuring activity would require smaller discrete units, such as the turn, than when coding negotiation activity, which would require a unit of analysis spanning several turns of interaction (see, for examle, Poole, 1983a).

To illustrate the actual process of coding, we will use the DFCS and GWRCS systems, shown in Figure 2, to categorise a short segment of interaction from a Group Model Building session with the same task and facilitator as the one mentioned earlier in the previous section. Participants are students in the role of managers at the Saturday Evening Post (Hall, 1976). Each has background information specific to their particular role, i.e. editor, publisher, circulation, production and president of the board. The student's task is to identify the reasons for the decline in profits over the last three years and identify options to turn the situation around. An experienced facilitator who is not a student is leading the group. The participants are 14 minutes into their one hour session.

\section{PLACE FIGURE 2 HERE}

\section{PLACE TABLE 2 HERE}

The DFCS and GWRCS require two different types of units before they can be applied to codify the data and both are indicated in first column of Table 2. To apply the DFCS we have taken the speaking turn as the interaction unit to be coded (cf. Poole \& Holmes, 1995; Weingart, 1997). The unitisation required for the GWCRS involves dividing the whole data segment into equally timed intervals of interaction, each representing a single (global) 
Franco, L.A. \& Rouwette, E.A.J.A. (2011). Decision Development in Facilitated Modelling Workshops. Submitted to the European Journal of Operational Research.

unit of 30 seconds. However, after 14 minutes 40 seconds a new interval in the GWRCS starts as the type of interaction changes. The GWRCS does allow for shorter time intervals if a change in codes occurs. The second column in Table 2 identifies the speaker. The last two columns show the codes for the DFCS and the GWRCS. The transcript shows how the participants try to find out how elements of the situation impact on one another. The facilitator keeps track of the discussion by capturing the main elements of the conversation in the model on a whiteboard visible to the participants.

The two coding systems illustrate two different perspectives on the conversation. The DFCS focuses on content and shows solution design (3b) and elaboration (3d), interspersed with evaluative reactions to proposals ( $3 \mathrm{~d}-$ and $3 \mathrm{~d}+$ ). The facilitator's contributions are either orientation (2a) or questions on the importance of solution elements (3d/). On the other hand, the GWRCS concentrates on relational aspects of group work, and shows how the group proceeds from focused work (1) to opposition leading to the formation of opposing sides (3a). This opposition is resolved through capitulation: one side gives in (3b). The group then reverts back to critical work (2). This illustrative example shows how coding schemes can be used to characterise the simultaneous and interacting development of decision content and process, a feature of group decision making that is acknowledged by both Eden $(1990,1992)$ and Phillips (Phillips \& Phillips, 1993).

Coding schemes must be both reliable and valid (Folger et al., 1984; Poole \& Folger, 1981a, 1981b). Reliability refers to the consistency of coding classifications across coders. Two types of reliability can be distinguished. 'Unitising reliability' (Guetzkow, 1950) implies consistency in the identification of interaction units to be classified with the coding scheme. Guetzkow's $U$, a measure of disagreement between two coders, calculates the difference between the number of units identified by an independent coder and the true number of units (the average of two coders' estimates) using a simple equation:

$$
U=\left(O_{1}-O_{2}\right) /\left(O_{1}+O_{2}\right)
$$

Where $U^{*} 100$ is the percent agreement and $O$ is the observer or coder. One shortcoming of this measure is that it focuses on agreement regarding the total number of units, rather than on a unit-by-unit agreement. Forger et al (1984) suggest the need for the use of a unit-byunit agreement measure when the units are subjective, the coding scheme is not exhaustive, or the data are to be used in sequential analyses (see Section 5.4).

'Classification reliability' refers to consistency in the assignment of interaction units to categories by different coders. The best measure of classification reliability is perhaps Cohen's kappa (1960), which measures the percentage agreement between two or more coders across categories, corrected by chance:

$$
\text { Kappa }=\left(P^{\prime}-P_{C}\right) /\left(1-P_{C}\right)
$$


Franco, L.A. \& Rouwette, E.A.J.A. (2011). Decision Development in Facilitated Modelling Workshops. Submitted to the European Journal of Operational Research.

Where $P^{\prime}$ is the observed percentage agreement among coders and $P_{C}$ is the proportion of chance agreement. One disadvantage of the above and other similar measures is that lower than would be expected estimates of reliability result when coding categories are not used with the same frequency. This occurs because more agreement is attributed to chance for the dominant categories than is necessary. When it is expected that observations will tend to be greatly skewed across categories within a giving coding scheme, Cohen (1968) suggests the use of a weighted kappa. Extensions of Cohen's kappa for more than two coders can be found in Fleiss (1971).

In addition to measure classification reliability for the entire coding system, category-bycategory measures of reliability must also be computed. This helps identify problem categories which will need to be refined. Low classification reliability may also be due to the quality of the coding which may suffer from 'coder's decay and drift' (Folger et al., 1984). This can be avoided if coders can refer continuously to a written coding manual, believe they are being randomly spot checked, and are able to train (and retrain) in appropriate coding strategies such as those described by Holsti (1969). Weingart (1997) recommends undertaking unitization and coding in separate passes because errors in unitizing will have a strong impact on classification reliability.

While consistency of unitization and classification is important when developing coding schemes, accuracy of interpretation is equally important. Validity relates to the degree to which a coding scheme taps into the information it was designed to obtain. Remember that coding schemes are designed to capture different types of meanings (see Section 5.2). If the scheme is aimed at capturing only observer-privileged meanings, then the same type of evidence used to assess face and construct validity for quantitative measures can be obtained to assess the coding scheme's validity. For face validity, the scheme should accurately embody the assumptions of the researcher's theory; be logically consistent; and its categories should be clearly defined in the view of the researcher and other knowledgeable observers. For construct validity, the empirical relationships between the theoretical constructs, as measured by the coding scheme, and other observables that are predicted by the researcher's theory, should be related as expected (Poole et al., 1999). For subject-privileged meanings, 'representational validity' should be demonstrated in addition to face and construct validity. Representational validity is indicated by whether the interpretations yielded by the coding system correspond to those of the group members, or the population to which the group members belong (for calculation procedures see Poole \& Folger, 1981a).

\subsection{Data analysis}

Although the study of FM workshop data can be conducted with purely ethnographic and conversational analyses methods (e.g. Horlick-Jones \& Rosenhead, 2002; Horlick-Jones \& Rosenhead, 2007), we are mainly concerned here with quantitative analyses that use interaction coding schemes such as those discussed above. 
Franco, L.A. \& Rouwette, E.A.J.A. (2011). Decision Development in Facilitated Modelling Workshops. Submitted to the European Journal of Operational Research.

The researcher wishing to study decision development within FM workshops is concerned mainly with the analysis of coded units in order to identify the sequential structure of these categorised units (Hirokawa, 1988). The choice of analytical method will be influenced by both the number of FM workshops available for examination, and the number of interaction units observed in the temporal development of group decisions. In the discussion that follows, we will assume that there will be a large number of interaction units observed within an FM workshop, but that the number of FM workshops accessible for study can vary from a few to many. For clarity of exposition, we will organise our discussion around two broad categories of analysis: frequency analysis and sequential analysis.

Frequency analysis uses absolute counts or relative frequencies to capture the composition of relevant communication and/or behaviour. Absolute frequencies provide information about the frequency of occurrence of a given behaviour, independent of the frequency of other behaviours that might have occurred. Relative frequencies control for the total amount of behaviour, and provide information about the proportional use of a given behaviour. Use of relative frequencies controls for the verbosity of the group and assumes that a speech act that occurs within a short interaction will have a stronger impact than the same speech act that occurs within a longer interaction. The choice of absolute or relative measures will be guided by theory. If it is believed that a given behaviour can influence group outcomes regardless of the amount of other behaviours present, absolute frequencies are more reflective. However, if one is interested in the relative impact of a given behaviour within the overall decision development interaction, relative frequencies might more appropriate. For example, striking a balance between divergent and convergent thinking behaviour during group decision making is well recognised within the FM field: too much emphasis on divergence will produce a never-ending increase in issues or options that is likely to lead to information overload. Similarly, early convergence implies that consensus has been reached without a thorough exploration of issues or options, which can lead to inferior decisions (Janis, 1972). Therefore, comparing absolute and relative frequencies of divergent and convergent thinking behaviours across groups (and within different phases of decision development) would shed light on each group's performance.

Frequencies of behaviours can be related to an independent and/or dependent variable using regression techniques. Questions that might be asked using this analytical approach are: How do FM workshop objectives influence the amount and type of group decision making behaviour? How does the amount of problem structuring or analysis, as opposed to solution analysis, affect the quality of, and satisfaction with, group decisions in FM workshops? How does the amount and type of appropriations of FM workshop structures affect group effectiveness?

Although useful in testing the relationship between interaction behaviours and outcomes, frequency analysis ignores the temporal context within which behaviours occur. Sequential analysis is predicated on the belief that social interaction has a temporal form, and thus fits neatly within a decision development lens. Rather than aggregating interaction data across 
Franco, L.A. \& Rouwette, E.A.J.A. (2011). Decision Development in Facilitated Modelling Workshops. Submitted to the European Journal of Operational Research.

time, relevant behaviours are treated as discrete units, with the goals of finding recurring patterns in the data. Patterns of decision development might result from specified inputs to the group, or predict performance outcomes. Several sequence analysis techniques are available (for a useful guide see Gottman \& Roy, 1990). Broadly speaking, these techniques look at transitions from one state (e.g. a type of behaviour) to another. Recurrent patterns are then identified and tested for significance. Below we briefly discuss three techniques that have been used extensively in decision development and process research (Poole et al., 2000), and are thus appropriate to the research strategy discussed here: Markov analysis, phasic analysis and optimal matching analysis.

Markov analysis is used to study micro-level interaction processes and assumes that, at any point in time, the probability of the next behaviour (e.g. group members engaged in open discussion about an issue) occurring depends on behaviours that occurred previously (e.g. groups members taking positions). The number of previous behaviours required to predict the current behaviour is called the 'order' of the Markov chain. Thus for a first-order Markov chain the distribution of the current behaviour depends only on the immediately previous behaviour. Current behaviour in a second-order Markov chain depends on the two immediately preceding behaviours, and so on. The behaviour that occurs at a given point in time is often called a 'state' of the process at that time. Transition matrices comprised of probabilities that current states follow prior states are analysed to determine the sequential structure in the data. For example, Poole and Dobosh (2010) recently used Markov analysis to test differences between the temporal trajectories of conflict and conflict management interaction in jury deliberations. Markov analysis would allow us to test differences in the ways FM participants respond to one another. It would help us answer questions such as: how are participants' tactical behaviours sequenced? Do participants match (reciprocate) or mismatch (fail to reciprocate) each other's behaviours? This would shed light into participants' attempts to maintain or redirect the prevailing decision path. Furthermore, by studying the content of these sequences, it would be possible to uncover the causes and consequences of matching tactical behaviours, to better understand the relationship between tactical behaviours and potential breakpoints in the decision path.

Phasic analysis studies interaction processes at a more macro-level of analysis, and thus offers an alternative to Markov analysis (Holmes \& Poole, 1991). In phasic analysis social events are believed to be divided into phases which may be linear or cyclical in nature. Process dynamics drive the shift in group behaviour from phase to phase. These phases consist of unified sets of acts that serve a particular function. The approach is based on the assumption that behaviour can be meaningfully grouped into units of coherent activity that are larger than individual acts, and which can be represented as timelines of group interaction activity. Figure 3 displays some illustrative examples of such timelines, drawn from research on GDSS reported by Sambamurthy and Poole (1992). Each of the timelines depicts different patterns of conflict management activity coded with the GWRCS system. Figure 3a shows a simple timeline that exhibits low levels of conflict. Figure 3b indicates moderately high levels of conflict that was resolved either by capitulation or tabling. Finally, Figure 3c depicts high levels of conflict and a pattern that resembles the normative 
Franco, L.A. \& Rouwette, E.A.J.A. (2011). Decision Development in Facilitated Modelling Workshops. Submitted to the European Journal of Operational Research.

model of conflict management: when conflict arises (as opposition), it is resolved collaboratively through open discussion. Techniques such as optimal matching, described next, can be used to determine the distance between timelines of actual sessions and the normative model.

\section{PLACE FIGURE 3 HERE}

Optimal matching analysis determines similarities between decision development sequences drawn from relatively small sets of possible elements (e.g. behaviours) (Sankoff \& Kruskal, 1983). This method measures the distance between two sequences in terms of the number of insertions, deletions, and substitutions required to transform one sequence into another. Once distances between all pairs of sequences in a data set (drawn from a sample of FM workshops) have been calculated, multi-dimensional scaling or clustering techniques can be used to identify similar development sequences and establishing differences between clusters. The resulting groupings can then be used to develop decision path typologies, conduct comparisons against hypothetical sequences drawn from theory, test for causal factors that create the difference between developmental sequences, or relate different decision paths to group outcomes (as suggested in section 4). For example, Poole and Holmes (Poole \& Holmes, 1995) have applied optimal matching analysis to compare decision development paths across groups working with and without group decision support systems.

\section{Conclusion}

Although the FM literature recognises the importance of the group process in FM workshops, little empirical research considers its dynamic nature. In this paper we proposed to address this gap in the literature by locating FM workshops as the focus of investigation, and adopting decision development as the analytical lens. Our paper set out to address three broad interrelated questions: (1) What patterns of decision development characterise FM workshops? (2) What is the relationship between these decision development patterns and FM workshop inputs and outputs? (3) How can we empirically study decision development in FM workshops? To this aim, we first reviewed the FM literature and revealed a few conceptualisations of how groups develop decisions, which we then mapped onto theoretical models from the group communication field. This approach seemed appropriate as both disciplines share an interest in group decisions develop making.

Our analysis suggested some potentially useful areas for the study of decision development within FM workshops that could help address the first two questions: decision paths, contingency factors, social construction processes, and the link between decision paths and workshop outcomes. We also articulated some tentative research questions and testable propositions within these areas. We addressed the third question by discussing the collection, treatment and analysis of workshop interaction data. Consequently, we covered a number of methodological issues concerning research design, coding scheme development, data coding and data analysis. Our discussion made it evident that our 
Franco, L.A. \& Rouwette, E.A.J.A. (2011). Decision Development in Facilitated Modelling Workshops. Submitted to the European Journal of Operational Research.

intended focus implies a very labour-intensive and time-consuming research process. We argue, however, that these efforts are more than justified by the ultimate benefit of significantly increasing our current understanding of 'what goes on' within FM workshops.

Despite its potential, interaction-based analysis of group processes is not without its critics in the FM field. Eden (1992), for example, has argued that although this type of studies are clearly valuable they are also very restrictive in their ability to judge the role of FM approaches in a real setting. We would contend that this is not always the case, as we have been able to collect audio/video recordings of 'real' FM workshops from our own practice. In addition, we posit that interaction analysis is a rigorous, systematic and reliable approach that can be undertaken not only in the field but also in the lab. Complementary insights derived from different research settings will significantly increase our understanding of a complex phenomenon.

At present, the feasibility of our proposal is somewhat limited by two aspects which seem to need attention by FM researchers in the short term. First, we need to recognise that whilst there is a multitude of coding systems available in the group communication literature, none of these were explicitly developed for a FM workshop context. For example, the DFCS used to code one the illustrative workshop transcript segment in the previous section, although a widely used and extensively validated coding system, does not capture all types of group activity that can occur in FM workshops to the same degree. The DFCS separates activities with regard to problem, solution, process, and other (simple (dis)agreements and tangents). However, whereas solution activity is well specified and consists of five subcategories, problem activity is less so. The DFCS comprises only aspects related to the analysis and critique of the problem facing the group. Clearly the level of specification for problem activity implied by this coding scheme could be improved to capture the richness of problem activity that is typical in most FM workshops (particularly facilitated problem structuring workshops). This is a clear avenue for immediate future work.

Similarly, other coding schemes are needed to capture social construction aspects of decision development in FM workshops. These aspects are particularly important to understand FM interventions, as implied by the conceptualisations of Eden and Phillips discussed in section 2. Coding schemes to capture social construction aspects of group interaction are currently not easily available. Poole and DeSanctis (1992) have designed a system to code structuration processes in technology-driven environments. However, similar coding systems are needed for the specific case of 'wide-band' environments (Eden, 1995).

Second, advancing the developmental agenda will require access to workshop data. This can be achieved through collaboration with other interested FM academic practitioners. We suggest that if we are to build a collective and usable database, the FM community needs to make the recording and sharing of (suitably anonymised) workshop data a 
Franco, L.A. \& Rouwette, E.A.J.A. (2011). Decision Development in Facilitated Modelling Workshops. Submitted to the European Journal of Operational Research.

standard practice. While confidentiality issues will make the access to recorded workshop data from client groups difficult for the researcher leading an intervention (let alone for those who are outside the intervention), an alternative data source might come from workshops in which students practise FM approaches. Clearly the latter type of workshop setting can be criticised because participants typically have only limited history and prospects of future work together (hence they are not responsible for implementing conclusions), and because these settings do not always include FM experts (Eden, 1995). Nevertheless, while we have to be careful in generalising results from simulated to realworld settings, the former offer certain advantages with regard to repeatability and controllability that a 'real' setting does not offer. Thus a twin-track approach to the collection of real and simulated FM workshop data is perhaps the most beneficial for advancing the field.

To conclude, it is frequently claimed that FM workshops result in beneficial group outcomes such as learning, higher decision quality and increased commitment to the way forward. Adopting our suggested focus would enable us to show how FM workshops, through the medium of decision development processes, influence these outcomes, clarifying the generative mechanisms behind their creation. It would allow us to identify different types of modelling sequences or FM analyst's strategies associated with particular group processes, outputs and outcomes, which can help develop best practice guidelines for teaching and training. It would also enable us to perform various interesting comparisons: of different FM approaches, of different expert FM analysts using the same approach, or of novice and expert FM analysts. Overall, a focus on FM workshops and the adoption of decision development as an analytical lens would serve the purpose of 'unpacking' the richness and complexity of FM approaches while, at the same time, systematically and rigorously testing their practical impact.

\section{Acknowledgements}

The authors wish to thank Marleen McCardle for her suggestions on coding schemes relevant to FM workshops.

\section{References}

Ackermann, F., \& Eden, C. (in press). Negotiation in Strategy Making Teams: Group Support Systems and the Process of Cognitive Change. Group Decision and Negotiation (doi: 10.1007/s10726-008-9133-y).

Bales, R. F. (1951). Interaction Process Analysis: a method for the study of small groups. Cambridge, MA: Addison-Wesley.

Bales, R. F., \& Cohen, S. P. (1979). SYMLOG: a system for the multiple level observation of groups New York: Free Press.

Barcus, A., \& Montibeller, G. (2008). Supporting the Allocation of Software Development Work in Distributed Teams with Multi-criteria Decision Analysis. OMEGA, 36(3), 464-475.

Brugha, C. (1998). The Structure of Development Decision Making. European Journal of Operational Research,, 104(1), 77-92.

Chang, A., Bordia, P., \& Duck, J. (2003). Punctuated Equilibrium and Linear Progression Toward a New Understanding of Group Development. Academy of Management Journal, 46(1), 106-117.

Chang, A., Duck, J., \& Bordia, P. (2006). Understanding the Multidimensionality of Group Development. Small Group Research, 37(4), 327-350. 
Franco, L.A. \& Rouwette, E.A.J.A. (2011). Decision Development in Facilitated Modelling Workshops.

Submitted to the European Journal of Operational Research.

Checkland, P. (1999). Soft Systems Methodology: a 30-year retrospective. Chichester: Wiley.

Cohen, J. (1968). Weighted kappa: Nomical scale agreement with provision for scaled dsagreement or partial credit. Psychological Bulletin, 70(4), 213-220.

Cohen, J. A. (1960). A Coeficient of Agreement for Nominal Scales. Education and Psychological Measurement, 20(1), 37-46.

Connell, N. (2001). Evaluating Soft OR: some reflections on an apparently 'unsuccessful' implementation using a Soft Systems Methodology (SSM) based approach. Journal of Operational Research Society, 52(1), 150-160.

De Geus, A. (1988). Planning as Learning. Harvard Business Review, 66(2), 70-74.

DeSanctis, G., \& Poole, M. S. (1994). Capturing the Complexity in Advanced Technology Use: adaptive structuration theory. Organization Science, 5(2), 121-147.

Donohue, W., Diez, M., \& Hamilton, M. (1984). Coding Natualistic Negotiation Interaction. Human Communication Research, 10(3), 403-425.

Eden, C. (1982). Problem construction and the influence of O.R. Interfaces, 12(2), 50-59.

Eden, C. (1986). Problem Solving or Problem Finishing. In M. Jackson \& P. Keys (Eds.), New Directions in Management Science (pp. 97-107). Aldershot: Gower.

Eden, C. (1988). Cognitive Mapping: a review. European Journal of Operational Research, 36(1), 1-13.

Eden, C. (1990). The Unfolding Nature of Group Decision Support: two dimensions of skill. In C. Eden \& J. Radford (Eds.), Tackling Strategic Problems: the role of group decision support (pp. 48-52). London: Sage.

Eden, C. (1992). A Framework for Thinking About Group Decision Support Systems. Group Decision and Negotiation, 1, 199-218.

Eden, C. (1993). From the Playpen to the Bombsite: the Changing Nature of Management Science. OMEGA: The International Journal of Management Science, 21(2), 139-154.

Eden, C. (1995). On Evaluating the Performance of "Wide-band" GDSS's. European Journal of Operational Research, 81(2), 302-311.

Eden, C. (2000). On Evaluating the Performance of GSS: furthering the debate by Paul Finlay - a response from Colin Eden. European Journal of Operational Research, 120(1), 218-222.

Eden, C. (2004). Analyzing Cognitive Maps to Help Structure Issues or Problems. European Journal of Operational Research, 159(3), 673-686.

Eden, C., \& Ackermann, F. (1998). Strategy Making: the journey of strategic management. London: Sage.

Finlay, P. (1998). On Evaluating the Performance of GSS: furthering the debate. European Journal of Operational Research, 107(1), 193-201.

Fisher, B. A. (1970). Decision Emergence: phases in group decision-making. Communication Monographs, 7, 53-66.

Fisher, B. A., Dreksel, G. L., \& Werbel, W. S. (1979). Social Information Processing Analysis (SIPA): coding ongoing human communication. Small Group Behavior, 10(1), 3-21.

Fisher, B. A., \& Stutman, R. K. (1987). An Assessment of Group Trajectories: analysing developmental breakpoints. Communication Quarterly, 35(2), 105-124.

Fleiss, J. L. (1971). Measuring Nominal Scale Agreement Among Many Raters. Psychological Bulletin, 76, 378-382.

Folger, J. P., Hewes, D. E., \& Poole, M. S. (1984). Coding Social Interaction. In B. Dervin \& M. Voight (Eds.), Progress in the Communication Sciences 4 (pp. 115-161). Northwood, NJ: Ablex.

Franco, L. A., Cushman, M., \& Rosenhead, J. (2004). Project Review and Learning in the UK Construction Industry: Embedding a Problem Structuring Method within a partnership context. European Journal of Operational Research, 152(3), 586-601.

Franco, L. A., \& Montibeller, G. (2010). Facilitated Modelling in Operational Research (Invited Review). European Journal of Operational Research, 205(3), 489-500.

Frey, L. R., Botan, C. H., Friedman, P. G., \& Kreps, G. L. (1992). Interpreting Communication Research: a case study approach. Englewood Cliffs, NJ: Prentice Hall.

Friend, J. (1993). Searching for appropriate theory and practice in multi-organizational fields. Journal of the Operational Research Society, 44(6), 585-598.

Friend, J. (1995). Supporting Developmental Decision Processes. International Transactions in Operational Research, 2(3), 225-232.

Friend, J. (1997). Connective Planning: from practice to theory and back. In E. Trist, F. Emery \& H. Emery (Eds.), The Social Engagement of Social Science Volume 3: the ecological perspective). Philadelphia: University of Pennsylvania Press.

Friend, J., \& Hickling, A. (2005). Planning Under Pressure: the strategic choice approach (3rd ed.): Elsevier. 
Franco, L.A. \& Rouwette, E.A.J.A. (2011). Decision Development in Facilitated Modelling Workshops.

Submitted to the European Journal of Operational Research.

Futoran, G. C., Kelly, J. R., \& McGrath, J. E. (1989). TEMPO: A time-based interaction system for analysis of group interaction process. Basic and Applied Social Psychology, 10, 211-232.

Gersick, C. J. G. (1988). Time and Transition in Work Teams: towards a new model of group development. Academy of Management Journal, 31(1), 9-41.

Gersick, C. J. G. (1989). Marking Time: predictable transitions in works groups. Academy of Management Journal, 32(2), 274-309.

Giddens. (1984). The constitution of society: Outline of the theory of structuration. Berkeley, CA: University of California Press.

Gottman, J. M., \& Roy, A. K. (1990). Sequential analysis: A guide for behavioral researchers. New York: Cambridge University Press.

Guetzkow, H. (1950). Unitizing and Categorizing Problems in Coding Qualitative Data. Journal of Clinical Psychology, 6(1), 47-58.

Hall, R. I. (1976). A system pathology of an organization: the rise and fall of the old Saturday Evening Post. Admnistrative Science Quarterly, 21(2), 185-211.

Hirokawa, R. Y. (1983). Group Communication and Problem-Solving Effectiveness: an investigation of group phases. Human Communication Research, 9(4), 291-305.

Hirokawa, R. Y. (1985). Decision Procedures and Decision-Making Perfomance. Human Communication Research, 12(2), 203-224.

Hirokawa, R. Y. (1988). Group Communication Research: considerations for the use of interaction analysis. In C. H. Tardy (Ed.), A Handbook for the Study of Human Communication: methods and instruments for observing, measuring, and assessin communication processes (pp. 229-245.). Norwood, NJ: Ablex.

Hirokawa, R. Y., \& Pace, R. (1983). A descriptive investigation of the possible communication-based reasons for effective and ineffective group decision making. Communication Monographs, 50, 363379.

Holmes, M. E., \& Poole, M. S. (1991). The Longitudinal Analysis of Interaction. In B. Montgomery \& S. Duck (Eds.), Studying Interpersonal Interaction). New York: Guilford.

Holsti, O. (1969). Content Analysis for the Social Sciences and the Humanities. Reading, MA: AddisonWesley.

Hopmann, P., \& Walcott, C. (1976). The Impact of International Conflict and Debate on Bargaining in Amrs Control Negotiations: an experimental analysis. International Interactions, 2(4), 189-206.

Horlick-Jones, T., \& Rosenhead, J. (2002). Investigating Risk Organizations and Decision Support Through Action Research. Risk Management, 4(4), 45-63.

Horlick-Jones, T., \& Rosenhead, J. (2007). The Uses of Observation: combining problem structuring methods and ethnography. 58, 5(588-601).

Hutchby, I., \& Wooffitt, R. (1998). Conversation Analysis. Cambridge: Polity Press.

Huz, S., Andersen, D. F., Richardson, G. P., \& Boothroyd, R. (1997). A framework for evaluating systems thinking interventions: an experimental approach to mental health system change. System Dynamics Review, 13(2), 149-169.

Jackson, M. H., \& Poole, M. S. (2003). Idea-generation in Naturally Occurring Contexts: complex appropriation of a simple group procedure. Human Communication Research, 29(4), 560-591.

Janis, I. L. (1972). Victims of Groupthink. Boston, MA: Houghton-Mifflin.

Kuhn, T., \& Poole, M. S. (2000). Do conflict management styles affect group decision making? Evidence from a longitudinal field study Human Communication Research, 26(4), 558-590.

Lim, S. G. S., \& Murnighan, J. K. (1994). Phases, deadlines, and the bargaining process. Organizational Behavior and Human Decision Processes, 58, 153-171.

Mabry, E. A. (1975). An Exploratory Analysis of a Developmental Model for Taask-Oriented Small Groups. Human Communication Research, 2, 66-74.

MacKenzie, K. D. (1979). A theory of group structures. New York: Gordon \& Breach.

McCartt, A., \& Rohrbaugh, J. (1989). Evaluating Group Decision Support System Effectiveness: a performance study of decision conferencing. Decision Support Systems, 5(2), 243-253.

McGrath, J. E. (1982). Dilemmatics - The study of research choices and dilemmas. In J. E. McGrath, J. Martin \& R. A. Kulka (Eds.), Judgement Calls in Research (pp. 69-61-62). Beverley Hills, CA: Sage.

Mingers, J., \& Rosenhead, J. (2004). Problem Structuring Methods in Action. European Journal of Operational Research, 152(3), 530-554.

Mintzberg, H., Raisinghani, D., \& Theoret, A. (1976). The Structure of 'Unstructured' Decision Processes. Administrative Science Quarterly, 21(2), 246-275.

Niederman, F., \& DeSanctis, G. (1995). The Impact of Structured Argument Approach on Group Problem Formulation. Decision Sciences, 26(4), 451-474. 
Franco, L.A. \& Rouwette, E.A.J.A. (2011). Decision Development in Facilitated Modelling Workshops. Submitted to the European Journal of Operational Research.

Nutt, P. (1984). Types of Organizational Decision Processes. Administrative Science Quarterly, 29, 414-450.

Nutt, P. (2008). Investigating the Success of Decision Making Processes. Journal of Management Studies, 45(2), 425-455.

Ormerod, R. (1995). Putting Soft OR Methods to Work: Information Systems Strategy Development at Sainsbury's. Journal of Operational Research Society, 46(3), 277-293.

Phillips, L. (1989). People-centred Group Decision Support. In G. Doukidis, F. Land \& G. Miller (Eds.), Knowledge-based Management Support Systems (pp. 208-224). Chichester: Ellis-Horwood.

Phillips, L. (1990). Decision Analysis for Group Decision Support. In C. Eden \& J. Radford (Eds.), Tackling Strategic Problems: the role of group decision support (pp. 142-150). London: Sage.

Phillips, L., \& Phillips, M. (1993). Facilitated Work Groups: theory and practice. Journal of Operational Research Society, 44(6), 533-549.

Poole, M. S. (1983a). Decision Development in Small Groups II: a study of multiple sequences in decision making. Communication Monographs, 50(3), 206-232.

Poole, M. S. (1983b). Decision Development in Small Groups III: a multiple sequence model of group decision development. Communication Monographs, 50(4), 321-341.

Poole, M. S. (1985). Tasks and Interaction Sequences: a theory of coherence in group decision making interaction. In R. L. Street \& J. N. Capella (Eds.), Sequence and Pattern in Communicative Behavior (pp. 206-224). London: Edwards Arnold.

Poole, M. S. (1999). Theories of Group Communication. In L. Frey, D. Gouran \& M. S. Poole (Eds.), Handbook of group communication: theory and research (pp. 37-70). Thousand Oaks, CA: Sage.

Poole, M. S., \& Baldwin, C. L. (1996). Developmental Processes in Group Decision Making. In R. Y. Hirokawa \& M. S. Poole (Eds.), Communication and Group Decision Making (pp. 215-241). Thousand Oaks, CA: Sage.

Poole, M. S., \& DeSanctis, G. (1992). Microlevel Structuration in Computer-Supported Group Decision Making. Human Communication Research, 19(1), 5-49.

Poole, M. S., \& Dobosh, M. (2010). Exploring Conflict Management Processes in Jury Deliberations Through Interaction Analysis. Small Group Behavior, 41(4), 408-426.

Poole, M. S., \& Doelger, J. A. (1986). Developmental Processes in Group Decision Making. In R. Y. Hirokawa \& M. S. Poole (Eds.), Communication and Group Decision Making (pp. 35-62). Beverly Hills, CA: Sage.

Poole, M. S., \& Folger, J. P. (1981a). A Method for Establishing the Representational Validity of Interaction Coding Schemes: do we see what they see? Human Communication Research, 8(1), 26-42.

Poole, M. S., \& Folger, J. P. (1981b). Modes of Observation and the Validation of Interaction Analysis Schemes. Small Group Behavior, 12(4), 477-493.

Poole, M. S., Folger, J. P., \& Hewes, D. E. (1987). Analyzing Interpersonal Interaction. In M. E. Roloff \& G. R. Miller (Eds.), Interpersonal Processes: new directions in communication research (pp. 220-256). Newbury Park, CA: Sage.

Poole, M. S., \& Holmes, M. E. (1995). Decision Development in Computer-Assisted Group Decision Making. Human Communication Research, 22(1), 90-127.

Poole, M. S., Keyton, J., \& Frey, L. R. (1999). Group Communication Methodology: issues and considerations. In L. R. Frey, D. S. Gouran \& M. S. Poole (Eds.), The Handbook of Group Communication Theory and Research (pp. 92-112). Thousand Oaks, CA: Sage.

Poole, M. S., \& Roth, J. (1989a). Decision Development in Small Groups IV: a typology of group decision paths. Human Communication Research, 15(3), 323-356.

Poole, M. S., \& Roth, J. (1989b). Decision Development in Small Groups V: test of a contingency model. Human Communication Research, 15(4), 549-589.

Poole, M. S., Seibold, D. R., \& McPhee, R. D. (1996). The Structuration of Group Decisions. In R. Y. Hirokawa \& M. S. Poole (Eds.), Communication and Group Decision Making (pp. 114-146). Thousand Oaks, CA: Sage.

Poole, M. S., Seinbold, D., \& McPhee, R. D. (1985). Group decision making as a structuration process. Quarterly Journal of Speech, 71(1), 74-102.

Poole, M. S., van de Ven, A. H., Dooley, K., \& Holmes, M. E. (Eds.). (2000). Organizational Change and Innovation Processes: theory and methods for research. New York: Oxford University Press.

Propp, K. M. (1997). Information utilization in small group decision making: A study of the evaluative interaction model." Small Group Research 28(3): 424-453. Small Group Research, 28(3), 424-453.

Putnam, L., \& Jones, T. (1982). Reciprocity in negotiations: An analysis of bargaining interaction Communication Monographs, 49(3), 171-191.

Reagan, P., \& Rohrbaugh, J. (1990). Group decision process effectiveness. A competing values approach. Group \& Organization Studies, 15(1), 20-43. 
Franco, L.A. \& Rouwette, E.A.J.A. (2011). Decision Development in Facilitated Modelling Workshops.

Submitted to the European Journal of Operational Research.

Rouwette, E. A. J. A., Vennix, J. A. M., \& van Mullekom, T. (2002). Group Model Building Effectiveness: a review of assessment studies. System Dynamics Review, 18(1), 5-45.

Sambamurthy, V., \& Poole, M. S. (1992). The Effects of Variations in Capability of GDSS Designs on Management of Cognitive Conflict in Groups. MIS Quarterly, 3(3), 224-251.

Sankoff, D., \& Kruskal, J. (1983). Time Warps, String Edits, and Macromolecules: the theory and practice of sequence comparison Reading, MA: Addison-Wesley.

Scheidel, T. M., \& Crowell, L. (1964). Idea Development in Small Discussion Groups. Quarterly Journal of Speech, 50, 140-145.

Schwartzman, H. B. (1989). The Meeting: gatherings in organizations and communities New York: Plenum.

Seibold, D., \& Meyers, R. (2007). Group Argument: A Structuration Perspective and Research Program. Small Group Behavior, 38(3), 312-336.

Sillars, A., Coletti, S. F., Parry, D., \& Rogers, M. A. (1982). Coding Verbal Conflict Tactics: non-vernal and perceptual correlates of the 'avoidance.distributive-integrative' distinction. Human Communications Research, 9(1), 83-95.

van Ginkel, W., \& van Knippenberg, D. (2008). Group Information Elaboration and Group Decision Making: the role of shared task representations. Organizational Behavior and Human Decision Processes, 105(1), 82-97.

Vennix, J. A. M. (1996). Group Model Building: facilitating team learning using System Dynamics. Chichester: Wiley.

Vennix, J. A. M. (1999). Group model-building: tackling messy problems. System Dynamics Review, 15(4), 379-401.

Vennix, J. A. M., Akkermans, H. A., \& Rouwette, E. A. J. A. (1996). Group model-building to facilitate organizational change: an exploratory study. System Dynamics Review, 12(1), 39-58.

Waller, M. J., Zellmer-Bruhn, M. E., \& Giambatista, R. C. (2002). Watching teh Clock: Group pacing behaviour under dynamic deadlines. Academy of Management Journal, 45(5), 1046-1055.

Weingart, L. R. (1997). How did they do that? The ways and means of studying group processes. In L. L. Cummings \& B. M. Staw (Eds.), Research in organizational behavior (pp. 184-239). Greenwich: JAI Press.

Weingart, L. R., Hyder, E. B., \& Prietula, M. J. (1996). Knowledge matters: The effect of tactical descriptions on negotiation behavior and outcome. Journal of Personality and Social Psychology, 70, 1205-1217.

Wheelan, S. (1994). Group processes: a developmental perspective. Boston: Allyn \& Bacon.

White, L. (2009). Understanding Problem Structuring Methods Interventions. European Journal of Operational Research, 99(3), 823-833. 
Franco, L.A. \& Rouwette, E.A.J.A. (2011). Decision Development in Facilitated Modelling Workshops. Submitted to the European Journal of Operational Research.

Table 1: Relation between selected conceptualisations of decision development in facilitated modelling and well-established theoretical models from group communication field.

\begin{tabular}{|c|c|c|c|}
\hline Approach & $\begin{array}{c}\text { Phase } \\
\text { models }\end{array}$ & $\begin{array}{l}\text { Social construction } \\
\text { models }\end{array}$ & Key references \\
\hline $\begin{array}{l}\text { Strategic } \\
\text { Choice }\end{array}$ & $\begin{array}{l}\text { Non-linear progression } \\
\text { of shaping, designing, } \\
\text { comparing, choosing } \\
\text { (multiple sequence) }\end{array}$ & & $\begin{array}{l}\text { Friend (1993, 1995) } \\
\text { Friend and Hickling } \\
(2005)\end{array}$ \\
\hline SODA & $\begin{array}{l}\text { Linear progression of } \\
\text { making sense, defining } \\
\text { issue, solution finding, } \\
\text { problem construction } \\
\text { (unitary sequence) } \\
\text { Balance between } \\
\text { ordered problem } \\
\text { representation and } \\
\text { social order. }\end{array}$ & $\begin{array}{l}\text { Use of models as } \\
\text { 'transitional objects' } \\
\text { that enables groups } \\
\text { members to construct a } \\
\text { shared reality. }\end{array}$ & $\begin{array}{l}\text { Eden (1982, 1992) } \\
\text { Eden and } \\
\text { Ackermann (1998) }\end{array}$ \\
\hline $\begin{array}{l}\text { Decision } \\
\text { Conferencing }\end{array}$ & $\begin{array}{l}\text { Balance between } \\
\text { process, group task and } \\
\text { emotional life. }\end{array}$ & $\begin{array}{l}\text { Airing emotional } \\
\text { content (breakpoints as } \\
\text { social construction } \\
\text { points) } \\
\text { Group members' } \\
\text { criteria for evaluating } \\
\text { Decision Conferencing } \\
\text { (decision logics as } \\
\text { structures that guide } \\
\text { interaction) }\end{array}$ & $\begin{array}{l}\text { Philips (1989, } \\
\text { 1990) } \\
\text { Phillips and Phillips } \\
\text { (1993) } \\
\text { (McCartt \& } \\
\text { Rohrbaugh, 1989; } \\
\text { Reagan \& } \\
\text { Rohrbaugh, 1990) }\end{array}$ \\
\hline
\end{tabular}


Franco, L.A. \& Rouwette, E.A.J.A. (2011). Decision Development in Facilitated Modelling Workshops. Submitted to the European Journal of Operational Research.

Figure 1: Raw group interaction segments excerpted from two facilitated modelling workshops.

Excerpt 1 (taken from SODA workshop; $F=$ facilitator; $P 1, P 2, P 3$, and $P 4=$ workshop participants)

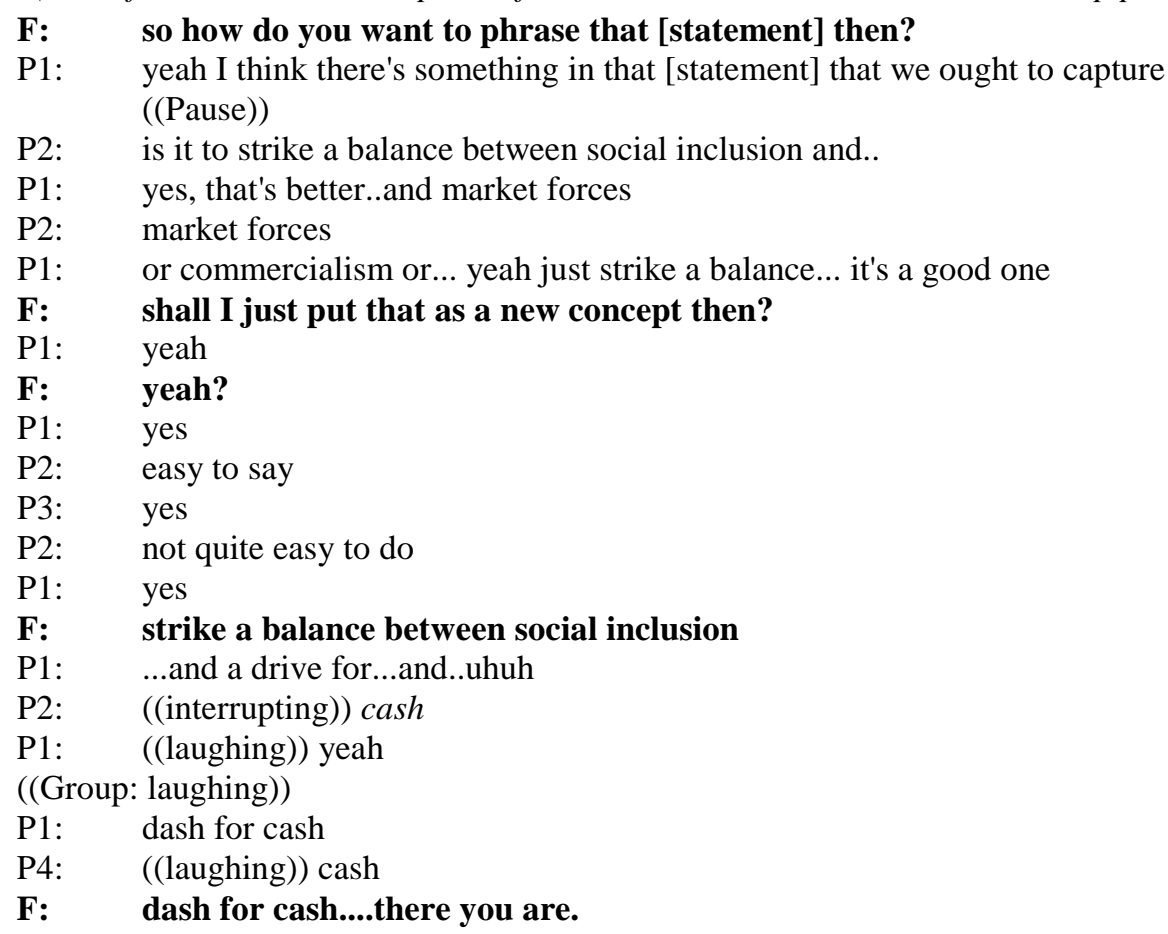

Excerpt 2 (taken from Group Model Building workshop; translated from Dutch; F = facilitator; P1, P2 and P3 = workshop participants)

F: $\quad$ Alright, I am looking at the time and we have twenty minutes left. Maybe all of us can have a look at the points where we can steer this problem in another direction. What is desired, what we can decide on to change. Ehm, maybe we can see if we change something, what will happen. Is that a po... does that have a positive or a negative effect on profits or maybe even both... What can we steer? What can we change?

P1: $\quad$ Production costs.

F: $\quad$ Production costs.

((puts a circle around the variable in model on whiteboard))

How?

P2: $\quad$ Try to decrease them.

F: Yes.

P3: Hmmm.

P1: $\quad$ Yes, reduce the number of pages. Yes, so that we create some revenues again.

F: $\quad$ Reducing the number of pages

((points to relations in model on whiteboard)).

But... if you lower this variable, the number of subscriptions will go down too, the revenues will decrease... But there is a cost reduction.

P2: Hmmm.

P3: Yes, uh, the question is how much the cost savings will be, and how much revenues or profit will be lower.

F: $\quad$ Yes. 
Franco, L.A. \& Rouwette, E.A.J.A. (2011). Decision Development in Facilitated Modelling Workshops. Submitted to the European Journal of Operational Research.

Figure 2: An example of two well-established interaction coding systems.

DECISION FUNCTIONS CODING SYSTEM (Poole and Roth 1989a; Poole and Holmes 1995)

Problem Activity

1a Problem Analysis: Statements that define or analyze the problem facing the group.

1b Problem Critique (+ or -): Statements that support or criticize a problem analysis.

Executive Activity

2a Orientation: Statements that direct the group's process or help the group do its work.

2b Process Reflection: Statements that comment on the group’s process or progress.

Solution Activity

3a Solution Analysis: Statements that define how the group will go about developing its solution in general terms, including criteria and general directions.

3b Solution Design: Statements that propose solutions.

3c Solution Elaboration: Statements that alter or amend solutions.

3d Solution Evaluation (+,-,/): Statements that support (+), criticize (-),or ask for evaluation of (/) solutions.

3e Solution Confirmation (+, /): Statements that ask for confirmations or votes (/) or offer final confirmation of decisions $(+)$.

Other

4 Tangents

5 Simple Agreement

$6 \quad$ Simple Disagreement

GROUP WORKING RELATIONSHIPS CODING SYSTEM (Poole 1983a)

Work-Focused Relationships

1 Focused Work: Periods when members are task focused and do not disagree with one another.

2 Critical Work: Periods when members disagree with each other, but the disagreements are centred on ideas and no opposing sides have been differentiated.

Conflict

3a Opposition: Periods in which disagreements are expressed through the formation of opposing sides.

3b Capitulation: A mode of resolution of opposition in which one side gives in.

3c Tabling: A mode of resolution of opposition in which the subject is tabled or dropped.

3d Open Discussion: A mode of resolution of opposition that utilizes problem-solving discussions, negotiation, or compromise.

Integration

4 Integration (e.g. laughter) 
Franco, L.A. \& Rouwette, E.A.J.A. (2011). Decision Development in Facilitated Modelling Workshops. Submitted to the European Journal of Operational Research.

Table 2: Sample of coded interaction from a simulated Group Model Building workshop

\begin{tabular}{|c|c|c|c|c|}
\hline Unit & Member & Transcript & $\begin{array}{l}\text { DFCS } \\
\text { code }\end{array}$ & $\begin{array}{l}\text { GWRCS } \\
\text { code }\end{array}$ \\
\hline 1. $14.00 \mathrm{~s}$ & 1 & $\begin{array}{l}\text { The number of readers has stayed more or less the same. In } \\
\text { eight years we, I mean we ... increased, once in a while we } \\
\text { decreased. You could call that constant. So apparently the } \\
\text { price does not matter, to the number of readers. }\end{array}$ & 3c & 1 \\
\hline 2. & 2 & $\begin{array}{l}\text { But maybe we attract fewer readers with a price this high. That } \\
\text { could be the case. That we are loosing readers because of that. }\end{array}$ & 3d- & \\
\hline 3. $14.30 \mathrm{~s}$ & 1 & But profits are increasing. & $3 \mathrm{~b}$ & 3a \\
\hline 4. & Fac & Shall I note this down? & $2 \mathrm{a}$ & \\
\hline 5. & 2 & No, profits are decreasing. & 3d- & \\
\hline 6. & 3 & No. & 6 & \\
\hline 7. $14.40 \mathrm{~s}$ & 2 & $\begin{array}{l}\text { The number of readers is going down, relatively speaking. The } \\
\text { relative growth in the number of readers has decreased. }\end{array}$ & $3 d-$ & $3 \mathrm{~b}$ \\
\hline 8. & 4 & And... the price for advertisers has remained the same. & $3 \mathrm{~d}$ & \\
\hline 9. & Fac & The price for advertisers, is that an important factor? & $3 \mathrm{~d} /$ & \\
\hline 10. & 2 & What? & $3 \mathrm{~d} /$ & \\
\hline 11. & Fac & $\begin{array}{l}\text { The price for advertisers, just mentioned by someone, is } \\
\text { that an important factor? }\end{array}$ & $2 \mathrm{a}$ & \\
\hline 12. & 2 & Well, maybe it is. & $3 \mathrm{~d}+$ & \\
\hline $13.15 .00 \mathrm{~s}$ & 4 & $\begin{array}{l}\text { That hasn't increased so much but I think you cannot let the } \\
\text { price for advertisements increase that much. }\end{array}$ & $3 c$ & 2 \\
\hline 14. & 1 & $\begin{array}{l}\text { Of course not, but... you will gain a lot of extra profits from } \\
\text { advertisements. }\end{array}$ & 3c & \\
\hline 15. & Fac & So advertisements are doing well? & $3 \mathrm{~d} /$ & \\
\hline 16. & 1 & Yes. & 5 & \\
\hline 17. & 2 & You might be able make it even better, maybe. & $3 d+$ & \\
\hline 18. & 1 & How do you mean, make advertising more expensive? & $3 \mathrm{~d} /$ & \\
\hline 19. & 4 & $\begin{array}{l}\text { Well, it says here that the advertising price, that that has } \\
\text { increased only little, in comparison to the subscription price. }\end{array}$ & $3 c$ & \\
\hline $20.15 .30 \mathrm{~s}$ & Fac & $\begin{array}{l}\text { OK, so this is maybe something that, something that we } \\
\text { could work on? }\end{array}$ & $3 \mathrm{~d} /$ & 2 \\
\hline 21. & 2 & Yes, that the advertising price could maybe be lowered a little & $3 \mathrm{~b}$ & \\
\hline
\end{tabular}


Franco, L.A. \& Rouwette, E.A.J.A. (2011). Decision Development in Facilitated Modelling Workshops. Submitted to the European Journal of Operational Research.

\begin{tabular}{|l|l|l|c|c|}
\hline & & bit, that the advertising costs go up. & & \\
\hline 22. & 1 & $\begin{array}{l}\text { Yes, but if you increase the advertising costs, then... this will } \\
\text { compare in such a way to... if you increase the advertising } \\
\text { costs more people will be able to advertise so you will have } \\
\text { less space to write an article in your magazine. }\end{array}$ & 3c \\
\hline
\end{tabular}


Franco, L.A. \& Rouwette, E.A.J.A. (2011). Decision Development in Facilitated Modelling Workshops. Submitted to the European Journal of Operational Research.

Figure 3: Examples of timelines (taken from Sambamurthy \& Poole 1992, p.241)

(a) Low conflict pattern

\begin{tabular}{|l|l|}
\hline FW & INT \\
\hline
\end{tabular}

Focused work (FW) followed by relational integration (INT).

(b) Moderately high conflict pattern

\begin{tabular}{|l|l|l|}
\hline FW & OPP.CAP & OPP.TABL \\
\hline
\end{tabular}

Focused work (FW) followed by opposition first resolved through capitulation (OPP.CAP); opposition then resurfaces to be resolved by tabling (OPP.TABL).

(c) High conflict pattern

\begin{tabular}{|l|l|l|l|}
\hline FW & INT & OPP & OD \\
\hline
\end{tabular}

Focused work (FW) followed by relational integration (INT); opposition (OPP) then surfaces to be resolved through open discussion (OD) (pattern resembles normative model of conflict management). 
Franco, L.A. \& Rouwette, E.A.J.A. (2011). Decision Development in Facilitated Modelling Workshops. Submitted to the European Journal of Operational Research.

\section{Appendix 1: Selected coding schemes relevant to facilitated modelling}

\begin{tabular}{|c|c|c|}
\hline Coding system & Focus & Authors \\
\hline $\begin{array}{l}\text { Interaction Process Analysis } \\
\text { (IPA) }\end{array}$ & Task and interpersonal process & Bales (1951) \\
\hline $\begin{array}{l}\text { SYstematic Multiple Level } \\
\text { Observation of Groups } \\
\text { (SYMLOG) }\end{array}$ & $\begin{array}{l}\text { Group member behaviour on three } \\
\text { dimensions: upward-downward, } \\
\text { positive-negative and degree of } \\
\text { acceptance authority }\end{array}$ & Bales and Cohen (1979) \\
\hline $\begin{array}{l}\text { Adaptive structuration theory- } \\
\text { based system }\end{array}$ & Appropriation moves & DeSanctis and Poole (1994) \\
\hline $\begin{array}{l}\text { Cue-Response Negotiation } \\
\text { Coding Scheme }\end{array}$ & $\begin{array}{l}\text { Strategic use of individual tactics } \\
\text { in negotiation }\end{array}$ & Donohue et al (1984) \\
\hline $\begin{array}{l}\text { Social Information Processing } \\
\text { Analysis (SIPA) }\end{array}$ & Information processes & Fisher et al (1979) \\
\hline Bargaining Process Analysis II & $\begin{array}{l}\text { Integrative and distribute } \\
\text { processes during negotiation }\end{array}$ & $\begin{array}{l}\text { Hopmann and Walcott (1976), } \\
\text { Putnam and Jones (1982) }\end{array}$ \\
\hline $\begin{array}{l}\text { Group Working Relationships } \\
\text { Coding System (GWRCS) }\end{array}$ & $\begin{array}{l}\text { Task and conflict oriented work } \\
\text { and integration }\end{array}$ & Poole (1983a), Sillars et al (1982) \\
\hline $\begin{array}{l}\text { Decision Functions Coding } \\
\text { System (DFCS) }\end{array}$ & $\begin{array}{l}\text { Problem, solution and group } \\
\text { process }\end{array}$ & $\begin{array}{l}\text { Poole and Roth (1989), Poole and } \\
\text { Holmes (1995) }\end{array}$ \\
\hline Evaluative interaction model & $\begin{array}{l}\text { Valence group gives to } \\
\text { information items, represented in } \\
\text { arguments exchanged }\end{array}$ & Propp (1997) \\
\hline $\begin{array}{l}\text { Conversational Argument Coding } \\
\text { Scheme (CACS) }\end{array}$ & $\begin{array}{l}\text { Development of argument } \\
\text { structure and sequences }\end{array}$ & Seibold and Meyers (2007) \\
\hline Information elaboration & $\begin{array}{l}\text { Degree to which information on } \\
\text { decision topics is elaborated in } \\
\text { discussion }\end{array}$ & $\begin{array}{l}\text { Van Ginkel and Van Knippenberg } \\
\text { (2008) }\end{array}$ \\
\hline
\end{tabular}

